\title{
MUJERES DE OTRO MUNDO
}

\section{WOMEN FROM ANOTHER WORLD}

Enrique Martínez Gutiérrez: Centro de Iniciativas de Cooperación al Desarrollo. Universidad de Alcalá de Henares. Madrid (España) enrique.martinez@uah.es

\section{CURRÍCULUM VITAE}

Secretario General del Centro de Iniciativas de Cooperación al Desarrollo (CICODE) de la Universidad de Alcalá de Henares (España). Autor de varios artículos científicos en libros y revistas universitarias.

\section{RESUMEN}

En la pasada década hemos asistido a un creciente reconocimiento internacional de los derechos específicos de la mujer. Esto coincide con el retraso e incluso el abandono en el que se encuentran dentro de muchas sociedades en vías de desarrollo. Por ello surgen muchas dudas sobre las políticas de desarrollo basadas en el llamado enfoque de género. El enfoque de género significa reforzar la presencia de las mujeres en las acciones que se emprenden y promover su papel dentro de la sociedad. El problema radica en la pervivencia de estructuras económicas y modelos de convivencia en los que la mujer apenas tiene oportunidad de dar los pasos más elementales que son necesarios para acometer la difícil tarea de su desarrollo personal, donde muchas veces aparece también la influencia de la cultura y la religión. 


\title{
PALABRAS CLAVE
}

Mujer - Derechos - Enfoque de Género - Políticas de Desarrollo

\begin{abstract}
In the past decade we have witnessed a growing international recognition of the specific rights of women. This coincides with the delay and abandonment in which are found within many developing societies. So many questions arise on development policies based on gender call. The gender approach means strengthening the presence of women in the actions undertaken and enhance their role in society. The problem is the persistence of economic structures and patterns of coexistence in which women have little opportunity to take the most basic steps that are necessary to undertake the difficult task of personal development, which often appears the influence of culture and religion.
\end{abstract}

\section{KEY WORDS}

Women - Rights - Gender Focus - Development Policy

\section{TEXTO:}

En la pasada década hemos asistido a un creciente reconocimiento internacional de los derechos específicos de la mujer. Al igual que en el caso de la infancia, los mayores, los discapacitados $\mathrm{u}$ otros sectores sensibles, el avance experimentado por la protección efectiva de esos derechos en las sociedades desarrolladas contrasta 
vivamente con el retraso e incluso el abandono en el que se encuentran dentro de muchas sociedades en vías de desarrollo.

El problema radica, como en otras tantas cuestiones vinculadas a la situación de desequilibrio global que se constata en el terreno social, en el reducido esfuerzo que se realiza por avanzar en las políticas con incidencia en la recuperación de la dignidad de la persona: educación, sanidad, empleo, integración, entre otras. Si de acuerdo con estadísticas generalmente aceptadas, el impacto y las consecuencias de la pobreza es mayor en las mujeres que en los varones o -lo que es lo mismo- de todos los pobres del mundo un $70 \%$ son mujeres, parece evidente que las políticas de igualdad no surten efecto alguno, antes bien pudieran considerarse políticas de desigualdad manifiesta.

Ello nos lleva a reflexionar, en modo alguno cuestionar, sobre las políticas de desarrollo basadas en el llamado enfoque de género. En la generalidad de los casos, enfoque de género significa reforzar la presencia de las mujeres en las acciones que se emprenden y promover su papel dentro de la sociedad. Sin embargo, pocas veces se cae en la cuenta de que la situación de desventaja de la mujer en el mundo en desarrollo tiene que ver con la pervivencia de estructuras económicas y modelos de convivencia en los que la mujer apenas tiene oportunidad de dar los pasos más elementales que son necesarios para acometer la difícil tarea de su desarrollo personal.

Muchas veces se trae a colación el componente cultural y religioso para explicar la situación de la mujer en entornos como el Islam o algunas comunidades indígenas en distintas partes del mundo. Tengo la impresión, no obstante, de que el problema de la mujer dentro de las sociedades en desarrollo es de orden estructural, independientemente del marco cultural o social en el que viva o del entorno en el que habite. El enfoque que se deba adoptar a la hora de tratar la integración social de la 
mujer en el ámbito rural o metropolitano o su condición de islámica o indígena es fundamentalmente una cuestión de perfiles. De algún modo se trata de abordar un problema común teniendo en cuenta estos prismas específicos.

¿Cuáles son los elementos básicos que conforman el desarreglo estructural en virtud del cual las mujeres del mundo en desarrollo tienen tantas dificultades para restaurar su dignidad como personas? Evidentemente, el hecho de que sean ellas las que soporten, en la mayoría de los casos, las cargas fundamentales del hogar, en particular la crianza de los hijos, determina que su acceso a los medios y el tiempo disponible para el desarrollo personal sea menor que en el caso de los varones. Ello implica que las políticas de educación, claves dentro del proceso de consecución del desarrollo, deberían reorientarse y adaptarse a la particular situación de la mujer que vive en estas sociedades. La escuela debe por tanto acercarse al hogar, aprovechando allí donde las condiciones de acceso lo permitan las ventajas que aportan las nuevas tecnologías, en particular la formación a través de la red. En un futuro próximo, buena parte de la capacitación se realizará por medios electrónicos, adecuadamente combinados con la formación presencial. ¿Porqué no avanzar desde ahora en el diseño de plataformas orientadas a la educación de personas, como las mujeres, que tienen que pasar la mayor parte del tiempo en sus casas atendiendo a las tareas domésticas? Este es un prerrequisito para su inserción en el mercado laboral y, por tanto, un basamento esencial de su independencia y desarrollo personal.

Existen además otros elementos estructurales que determinan la presencia de desigualdades entre géneros. Entre ellos hay que destacar los que afectan a la higiene y la salud reproductiva. La mujer se encuentra en muchas sociedades en desarrollo al albur de las circunstancias a la hora de programar su proyecto familiar y de hacerlo en unas condiciones suficientes para no tener que sumar a su condición de pilar fundamental para el sostenimiento del hogar, la de responsable de una prole enferma o discapacitada, por no hacer mención del esfuerzo que conlleva sobrellevar el 
embarazo o sus propias dolencias. Los avances en este campo han sido considerables en los últimos años, pero un porcentaje altísimo de mujeres no dispone en la actualidad de acceso a los programas de higiene y salud reproductiva. La planificación familiar, tan necesaria en buena parte de las sociedades del mundo en desarrollo, es por completo inabordable sin que la mayoría de la población, femenina pero también masculina, pueda disponer de conocimientos apropiados y acceso a los medios técnicos y humanos que le sirvan para reorientar su concepto de la higiene y de la salud.

Por último, hay que destacar un elemento fundamental que se añade al elenco -por otra parte inabordable en un repaso tan somero como éste- de los problemas de la mujer dentro del mundo en desarrollo. Me refiero a la lacra de la violencia familiar. Millones de mujeres - por supuesto también de niños- sufren agresiones de todo tipo por parte de los varones de su entorno. En la actualidad se ha entablado un amplio debate en torno a los orígenes y causas de la violencia familiar o de grupo. Desde el alcoholismo al exceso de trabajo, pasando por desequilibrios más sutiles, y no por ello menos graves, generados desde la publicidad y las imágenes difundidas por los medios de comunicación, son muchas las causas que determinan situaciones incompatibles con la dignidad de la persona. Las autoridades públicas tienen por delante una compleja tarea a la hora de tratar de desarraigar la práctica de la violencia en el entorno familiar. En este sentido, las políticas educativas vuelven a situarse en el centro de la cuestión. Pero la educación dirigida no sólo a los protagonistas de la vida doméstica o familiar, sino también al conjunto del entorno en el que esta se desarrolla, porque una sociedad formada y concienciada es una sociedad que actúa como freno de conductas violentas. La erradicación de la violencia en el entorno familiar tan solo puede darse desde un clima de reprobación moral de conjunto de estas prácticas. En este sentido, las campañas a través de medios de comunicación deben reforzarse, con más intensidad si cabe, en los países 
en desarrollo, donde los índices de seguimiento de medios como la televisión son altísimos.

Todas estas cuestiones están en la agenda internacional y en el debate público. Sin embargo, parece que todavía desde los países desarrollados no se es consciente de la situación en que viven millones de mujeres en el mundo. Mujeres que además de contribuir destacadamente al crecimiento y la riqueza de sus países garantizan el sostenimiento de las estructuras familiares y sociales básicas para el desarrollo. ¿Por qué se les niega entonces la oportunidad de restaurar su dignidad como personas y poder, de este modo, a través de sus conocimientos y sus habilidades aportar aún más a ese desarrollo? En definitiva, quisiera en el Día Internacional de la Mujer llamar la atención de todos para que contribuyéramos a que millones de mujeres en el planeta dejaran definitivamente de parecer mujeres de otro mundo.

http:/ / portalfio.org/inicio/index.php?option=content\&task=view\&id=90\&Itemid=2 